\title{
Satisfação conjugal em casamentos de longa duração: uma construção possível
}

\author{
Maria de Betânia Paes Norgren \\ Instituto Sedes Sapientiae, São Paulo \\ Rosane Mantilla de Souza \\ Pontifícia Universidade Católica de São Paulo \\ Florence Kaslow \\ Duke University (EUA) \\ Helga Hammerschmidt \\ Clínica Grosshadern (Alemanha)
}

Shlomo A. Sharlin

Universidade de Haifa (Israel)

\begin{abstract}
Resumo
O relacionamento conjugal está associado à saúde e qualidade de vida, principalmente nos anos de maturidade e velhice, embora o fato de um casamento durar não necessariamente signifique que o mesmo é satisfatório para os cônjuges. O objetivo do presente estudo foi identificar os processos e variáveis associadas à satisfação conjugal em casamentos de longa duração, ou seja, mais de 20 anos. Trinta e oito casais paulistas responderam a um conjunto de questionários já utilizados em estudo multicultural prévio (Estados Unidos, Suécia, Alemanha, Holanda, Canadá, África do Sul, Israel e Chile). Em cerca de metade dos casais estudados, ao menos um dos cônjuges estava satisfeito. Comparando-se casais satisfeitos e insatisfeitos foi possível identificar que a satisfação aumenta quando há proximidade, estratégias adequadas de resolução de problemas, coesão, boa habilidade de comunicação, se os cônjuges estiverem satisfeitos com seu status econômico e forem praticantes de sua crença religiosa.

Palavras-chave: casamento; casamento de longa duração; satisfação conjugal
\end{abstract}

\begin{abstract}
Marital satisfaction in long lasting marriages: a feasible construction. Marital relationship is related with couple's health and quality of life, especially during the adulthood and the aging years. However, the fact that a marriage is long lasting, does not mean it is necessarily satisfactory to the partners. This paper aims to identify the processes and variables associated to satisfaction in long lasting marriages (those longer than 20 years). Thirty eight couples from São Paulo, Brazil, answered a set of questionnaires used previously in multicultural studies carried out in Sweden, USA, Germany, Canada, Netherlands, South Africa, Israel and Chile. In about half of these couples, at least one consort was found satisfied. Comparing satisfied and unsatisfied couples, it became clear that higher levels of satisfaction are found among couples who have adequate strategies for problem solving, proximity, cohesion, good communication skills; who are religiously active and satisfied with their economical status.
\end{abstract}

Keywords: marriage, long lasting marriages, conjugal satisfaction

$\mathrm{O}$ s relacionamentos íntimos são aspecto central da vida adulta e a qualidade dos mesmos tem implicações não só na saúde mental, mas também na saúde física e vida profissional de homens e mulheres. Em vista disso, ao longo do século $\mathrm{XX}$, os pesquisadores demonstraram interesse crescente em compreender a vida amorosa e conjugal, bem como avaliar a qualidade desses relacionamentos. As revisões de literatura existentes acerca da satisfação na conjugalidade (Dela Coleta, 1989; Hicks \& Platt, 1970; McNamara \& Bahr, 1980; Spanier \& Lewis, 1980) afirmam que até os anos de 1960 os estudos visavam predizer a viabilidade das relações conjugais, analisando características prognósticas, e a partir daí, propuseram-se a construir modelos, avaliando os relacionamentos em si mesmos, na busca de 
uma compreensão mais ampla dos processos envolvidos nas relações satisfatórias.

Satisfação conjugal é, sem dúvida, um conceito subjetivo, implicando em ter as próprias necessidades e desejos satisfeitos, assim como corresponder, em maior ou menor escala, ao que o outro espera, definindo um dar e receber recíproco e espontâneo. Relaciona-se com sensações e sentimentos de bem-estar, contentamento, companheirismo, afeição e segurança, fatores que propiciam intimidade no relacionamento, decorrendo da congruência entre as expectativas e aspirações que os cônjuges têm, em comparação à realidade vivenciada no casamento (Campbell, Converse, \& Rogers, 1976; Chadwick, Albrecht, \& Kunz, 1976; Farias, 1994; Gottman \& Krokoff, 1989; Lewis \& Spanier, 1979; Miranda, 1987; Olson 1986; Olson \& Stewart, 1991; Rollins \& Cannon, 1974). Além disso, Farias (1974) identificou não haver diferença quanto ao alto nível de expectativa para com o casamento em casais satisfeitos ou insatisfeitos, mas sim entre as expectativas e o que vivenciam na realidade atual.

Em termos gerais, reconhece-se hoje que a satisfação conjugal é fenômeno complexo, no qual interferem diversas variáveis, tais como: características de personalidade, valores, atitudes e necessidades; sexo, momento do ciclo da vida familiar, presença de filhos, nível de escolaridade, nível socioeconômico, nível cultural, trabalho remunerado e experiência sexual anterior ao casamento (Dela Coleta, 1989; Olson, 2000; Sharlin, Kaslow, \& Hammerschmidt, 2000; Spanier \& Lewis, 1980).

Deve-se observar ainda que o casamento transforma-se ao longo do ciclo de vida familiar, e assim, o nível de satisfação também varia com o decorrer dos anos de convívio (Gottman \& Krokoff, 1989; Olson, 1988; Rollins \& Cannon, 1974; Rollins \& Feldman, 1970; Weigel \& Ballard-Reisch, 1999). Quando um casal permanece junto por longo tempo, no entanto, não significa necessariamente que tenham um bom relacionamento. Kaslow e Hammerschmidt (1992) bem como Spanier e Lewis (1980) diferenciam satisfação e estabilidade conjugal. Argumentam poder existir casamentos estáveis e não necessariamente satisfatórios, que se mantêm pelas mais variadas razões: um ou ambos os cônjuges abominam a idéia do divórcio, por razões pessoais ou por credo religioso; podem ter medo da mudança e da solidão; não conseguem lidar com a liberdade e auto-suficiência; não querem repartir o patrimônio que construíram ao longo dos anos e, finalmente, estar casado e fazer parte de uma família pode ser menos ansiógeno do que estar descasado.

Quando se pensa em relacionamentos conjugais de longa duração - com mais de 20 ou 25 anos - deve-se considerar que estes casais já passaram por várias transformações na sua relação conjugal e familiar. Quanto à fase do ciclo de vida familiar, se tiverem filhos, eles podem ser adolescentes, jovens ou adultos e os próprios cônjuges devem estar, pelo menos, na meia idade. Apesar de atualmente este período ser visto como época de novas oportunidades e expansão de vida, é momento também de rever o que foi feito até então: conquistas, ganhos, decepções e perdas; portanto, de projetar e redirecionar o futuro, corrigir o rumo e - por que não? o casamento. $\mathrm{Na}$ fase do ciclo vital familiar que envolve os casais idosos, o cuidado dos filhos deixa de ser uma tarefa central, a vida profissional perde destaque ou se interrompe e os cuidados com a saúde se agravam. Seja como for, em ambas as fases o casal tem mais tempo para ficar junto.

Muitos casamentos não sobrevivem à saída, ou mesmo à independência dos filhos, e o divórcio acontece após 20 anos ou mais de casados. No Brasil, de acordo com dados do Instituto Brasileiro de Geografia e Estatística, em 2001, 15\% das separações judiciais concedidas em primeira instância ocorreram entre 15 e 19 anos de casamento e $19 \%$ com 20 anos ou mais. Esses casais parecem não ser capazes ou não desejarem transformar sua relação, revendo a conjugalidade, dando-lhe, neste momento, maior destaque do que às questões familiares. Um ou ambos talvez desejem algo diferente do que seu casamento propicia e, como seus filhos, acreditem que têm de deixar a casa, embarcar numa nova vida e realizar seus sonhos.

As relações duradouras e satisfatórias, por outro lado, permitem que o sistema conjugal se torne um refúgio em relação aos estressores externos, bem como a matriz para o contato com outros sistemas sociais (Minuchin, 1990), o que é bastante relevante frente à longevidade crescente da população idosa. Desse modo, a relação conjugal pode se transformar em fonte de crescimento pessoal e aprendizagem, se houver espaço para as diferenças e trocas pessoais. Gagnon, Hersen, Kabacoff e van Hasselt (1999) investigaram os aspectos interpessoais e psicológicos associados à satisfação nos relacionamentos conjugais duradouros, notando que essas relações beneficiam-se do baixo nível de conflito e aumento das fontes de prazer mútuo, por não terem mais filhos para criar. Além disso, a percepção do apoio que o cônjuge pode prover parece estar positivamente relacionada à satisfação conjugal e bem-estar geral das mulheres mais velhas. Contudo, se os membros do casal estimularem os aspectos negativos um do outro, o relacionamento conjugal pode se tornar conturbado e conflituoso.

Não há somente os extremos satisfatório e insatisfatório nos relacionamentos duradouros. Weishaus e Field (1988) realizaram estudo com casamentos que variavam de cinqüenta a sessenta anos de duração e identificaram seis tipos conjugalidade: estável/positivo (os membros do casal mantiveram satisfação de moderada a alta e afeto positivo durante todo seu casamento); estável/neutro (casais satisfeitos, mas que nunca sentiram grande afeto um pelo outro); estável/ negativo (afeto negativo desde o início da relação); curvilinear (a satisfação entre os membros do casal declinou nos primeiros estágios do ciclo vital da família, mas aumentou nos últimos anos); declínio contínuo (no início havia alto nível de satisfação, mas decresceu paulatinamente) e aqueles com aumento contínuo (fenômeno que acontecia em casamentos arranjados, raros no Ocidente).

Em outro trabalho a respeito dos casamentos de longa duração, Fennel (1987) estudou uniões de mais de vinte anos, nas quais encontrou as seguintes características importantes entre os cônjuges: compromisso com a relação; respeito pelo outro como melhor amigo; lealdade para com o mesmo e expectativa de reciprocidade; abertura mútua; valores morais fortes e compartilhados; compromisso com a fidelidade sexu- 
al; desejo de ser um bom pai; fé em Deus e compromisso espiritual. Destacou-se ainda a camaradagem entre os cônjuges, incluindo passar uma quantidade de tempo considerável e agradável juntos.

Lauer, Lauer e Kerr (1990) realizaram pesquisa com casais entre quarenta e cinco e sessenta anos de relacionamento e identificaram como variáveis importantes para a satisfação: estar casado com alguém que se valorize como pessoa e aprecie estar junto; compromisso com o cônjuge e com o casamento; senso de humor; consenso sobre vários assuntos, tais como objetivos e projeto de vida, amigos e tomada de decisão. Notarius e Markman (1993) encontraram resultados semelhantes, em estudo de diferentes estágios do ciclo da vida familiar, e a investigação de Gottman (1994) que se baseou nesta última, descreveu três tipos de casamentos estáveis: validador, evitador e volátil. $\mathrm{O}$ autor considera aspectos preocupantes num relacionamento a crítica, o desprezo, a defesa e a teimosia.

Confirmando aspectos relevantes encontrados em todas essas investigações, Kaslow e seus diversos colaboradores (Kaslow \& Hammerschmidt, 1992; Kaslow, Hanson, \& Lundblad, 1994; Kaslow \& Robinson, 1996; Sharlin, Kaslow, \& Hammerschmidt, 2000) buscaram identificar as características diferenciais dos casamentos satisfatórios de longa duração em diferentes países e a publicação de Sharlin et al. (2000) descreve a primeira discussão multicultural apresentando os estudos realizados nos Estados Unidos, Suécia, Alemanha, Holanda, Canadá, África do Sul, Israel e Chile. Seus resultados permitiram concluir que em diferentes países as uniões satisfatórias caracterizam-se por apresentar: boa habilidade de resolução de conflitos; confiança entre os cônjuges; compromisso com o outro; apreciação, amor e respeito mútuos; habilidade em dar e receber; comunicação aberta e honesta entre os parceiros; sensibilidade aos sentimentos do outro; sistema de valores e interesses em comum; crença na dimensão espiritual da vida. Trata-se de relações mais flexíveis e igualitárias na distribuição de poder. Além disso, os cônjuges apresentam senso de pertencimento e envolvimento e parecem ser capazes de lidar com as crises e transições que a vida apresenta, estando mais orientados pelo presente e futuro do que pelos fatos passados da vida. Eles gostam de passar o tempo juntos, de se divertir, são bons amigos e valorizam o aspecto sexual do seu relacionamento.

Nesse estudo os motivos dados pelos cônjuges para permanecem juntos foram: acreditarem que o casamento é parceria para a vida toda, sentirem-se responsáveis um pelo outro e por haver amor. Esses motivos foram apresentados nessa ordem pelos cônjuges norte-americanos e canadenses e constaram entre os seis primeiros motivos apontados em todos os países estudados, com exceção do Chile. Nesse país, único de maioria católica estudado e no qual não existia lei de divórcio até 2004, apesar de os participantes considerarem o casamento uma parceria para toda a vida, acreditavam, também, que as crises são inevitáveis e promovem crescimento pessoal. Vale ainda ressaltar que nesse estudo multicultural, os mais altos índices de satisfação conjugal foram obtidos no Chile e na Suécia.
De modo a dar prosseguimento a esta investigação em outros paises, o presente trabalho avaliou os casamentos de longa duração no Brasil, por ora com uma amostra de paulistas, buscando identificar as variáveis e dimensões que contribuem para um relacionamento conjugal de longa duração, satisfatório.

\section{Método}

\section{Participantes}

Os 38 casais que participaram da pesquisa eram representantes da população em geral (não clínica), residentes na Região Metropolitana de São Paulo. Tratou-se de uma amostra de conveniência e foram usados como critérios de inclusão: estarem casados há pelo menos 20 anos e pertencerem às chamadas camadas médias da população, pois se partiu do pressuposto de que teriam grau de escolarização que permitisse responder aos questionários do procedimento, os quais requerem boa capacidade de compreensão da linguagem escrita. $\mathrm{O}$ fato de não ser a primeira união conjugal dos participantes não foi considerado critério de exclusão.

$\mathrm{Na}$ amostra, em média, os cônjuges estavam casados há 29 anos, numa dispersão de 20 a 47 anos; os homens tinham idade entre 44 e 73 anos e eram, em média, quatro anos mais velhos do que as mulheres, cuja idade variou de 42 a 71 anos. Os casais tinham de zero a sete filhos, e em média, dois; dentre eles, apenas um estava no segundo casamento do marido, todos os demais eram primeiros casamentos.

Levando em consideração os dados da ficha dos participantes, o que se observou é que embora não seja uma amostra ao acaso, o grupo estudado reflete a camada média alta da população brasileira, e tem perfil semelhante às demais amostras do estudo de Sharlin et al. (2000). Tanto homens como mulheres apresentaram nível educacional alto, sendo que $66,7 \%$ concluíram o terceiro grau ou a pós-graduação. Em geral, a maioria estava satisfeita com a sua situação financeira $(82,5 \%)$ e saúde física $(90 \%)$. A maior parte dos homens $(68 \%)$ trabalhava o dia todo, alguns (26\%) em tempo parcial e uma pequena parcela $(16 \%)$ não exercia atividade remunerada (aposentados). A maioria das mulheres (47\%), apesar de ter qualificação similar à dos homens, trabalhava em período parcial; uma pequena parcela (16\%) trabalhava o dia todo e um terço delas não exercia atividade remunerada.

Dos participantes, $90 \%$ identificaram-se como católicos, dos quais $63 \%$ praticantes. Os demais se dividiram em porcentagens iguais de espíritas, protestantes, evangélicos e judeus.

\section{Procedimento}

Foi utilizado o mesmo procedimento desenvolvido por Kaslow e Hammerschmitd (1992). Devido ao fato de indivíduos casados há mais de 20 anos não serem atualmente tão freqüentes na população, inicialmente foi feita uma divulgação na rede pessoal das pesquisadoras acerca do objetivo do estudo, da necessidade de participantes que preenchessem os critérios de inclusão e, considerando o fato de o casamento ser concebido como indissolúvel entre os católicos e da necessi- 
dade de atingir indivíduos de diferentes credos religiosos. A partir daí, alguns casais foram indicados por amigos e colegas e outros foram sendo indicados pelos próprios participantes, segundo um procedimento denominado bola de neve.

Os participantes em potencial eram contatados primeiramente por quem os indicara e verificada a disponibilidade para receber um telefonema de uma das pesquisadoras. Quando concordavam, uma delas ligava, explicava os objetivos e procedimento da pesquisa.

Caso o casal aceitasse participar, era-lhes enviado envelope contendo dois conjuntos de questionários idênticos, (a não ser pela cor: amarelo e azul, para serem preenchidos por mulheres e homens respectivamente), uma carta de apresentação explicitando o objetivo do trabalho, instruções para o preenchimento - que destacava a solicitação de que os cônjuges respondessem isoladamente - o telefone de uma das pesquisadoras para contato por qualquer motivo necessário, bem como um envelope selado para retorno do material. Para garantir sigilo e privacidade, uma das pesquisadoras brasileiras era colocada tanto como remetente quanto destinatária dos questionários.

Foram enviados 100 envelopes com o material e definido um período de retorno de 6 meses. Houve uma devolução de 42 em tempo hábil, dos quais quatro foram excluídos devido à presença de apenas um respondente, redundando em $38 \mathrm{ca}$ sais na amostra.

\section{Instrumento}

Foi utilizado o instrumento desenvolvido por Kaslow e Hammerschmidt (1992) que já servira de base para os estudos nos diferentes paises (Kaslow \& Hammerschmidt, 1992; Kaslow, Hanson \& Lundblad, 1994; Kaslow \& Robinson, 1996; Sharlin, et al. 2000), o qual consiste em um conjunto de seis questionários respondidos independentemente da presença do aplicador. O material foi traduzido, adaptado, pré-testado e revisado sistematicamente, até atingir-se um consenso quanto ao significado de cada item.

$\mathrm{O}$ instrumento cobre o conjunto de temas associados à satisfação conjugal. Embora os seis questionários, enquanto instrumento geral, tenham sido organizados por Kaslow e Hammerschmidt (1992), apenas os questionários de informações gerais, a lista de classificação de problemas, a lista de motivos que levam o casal a permanecer junto e a lista de componentes da satisfação conjugal são de autoria das mesmas. Os outros dois questionários são de autores consagrados na literatura sobre satisfação conjugal e relacionamento familiar já amplamente utilizados. A escala de ajustamento conjugal (DAS - Dyadic Ajustment Scale) é de autoria de Spanier (1976) e o Questionário de avaliação de estratégias de resolução de conflito e comunicação (HSP - Health and Stress Profile) é de autoria de Olson e Stewart (1991).

Embora exija menos de 30 minutos para ser respondido, trata-se de material extenso, impossível de ser reproduzido no presente artigo, mas que, em caso de maior interesse do leitor, pode ser enviado. Em seguida, descreve-se brevemente cada um dos questionários.

\section{Questionário de informações gerais}

Tem a forma de itens para completar e de múltipla escolha. Cobre dados pessoais (sexo, idade, naturalidade, estado civil, religião, escolaridade, atividade desenvolvida); autoavaliação de situação financeira, da qualidade de vida na infância e do casamento dos pais; informações sobre a história do relacionamento conjugal (tempo de namoro, idade ao casar, tempo de casamento, idade dos filhos).

\section{Escala de ajustamento conjugal}

\section{(DAS - Dyadic Ajustment Scale, Spanier, 1976)}

Composta por 32 itens (30 dos quais em escalas de 6 pontos e 2 itens sim ou não) investiga a percepção que os parceiros têm do relacionamento, avaliando quatro dimensões, que definem quatro sub-escalas: consenso, satisfação, coesão e expressão de afeto.

\section{Lista de classificação de problemas}

Contém 20 itens em forma de escala de cinco pontos, cobrindo os temas de filosofia de vida, valores, questões financeiras, lazer, amizades, educação de filhos, carreira, espaço pessoal, casos extraconjugais, ciúmes, temperamento do cônjuge. Uma alta pontuação indica consenso, ou não existência de conflito.

Questionário de avaliação de estratégias de resolução de conflito e comunicação (HSP Health and Stress Profile, Olson \& Stewart, 1991)

É composto de 40 escalas de cinco pontos as quais avaliam a capacidade de comunicação conjugal (dez itens), a capacidade de resolução de problemas (dez itens) e o relacionamento conjugal em termos de coesão (dez itens) e flexibilidade (dez itens).

\section{Lista de motivos que levam o casal a permanecer junto}

Cada participante deve assinalar três razões, entre as 45 apresentadas, que melhor representam os motivos que o levam a continuar casado no momento atual, e três motivos que o levaram a continuar casado no momento mais difícil do relacionamento. Os motivos referem-se a motivações intrínsecas ao parceiro ou à conjugalidade, valores e crenças, normas e expectativas sociais, solução positiva de problemas, motivos econômicos ou de ordem prática e motivos neuróticos.

\section{Lista de componentes da satisfação conjugal}

Apresenta 42 itens relativos a componentes de um relacionamento. Por exemplo: confiança mútua, respeito mútuo, amor, lealdade, segurança econômica, relacionamento igualitário, humor e alegria, atratividade do cônjuge, os quais devem ser assinalados como presentes, ou que os participantes gostariam que existisse no relacionamento conjugal.

\section{Resultados}

Inicialmente foi calculado o grau de satisfação entre todos os participantes, usando-se os resultados da sub-escala 
de satisfação da Escala de ajustamento conjugal (DAS Dyadic Ajustment Scale, Spanier, 1976). Para evitar problemas relativos ao estabelecimento de nota de corte para delimitar os grupos de casais satisfeitos, medianamente satisfeitos e insatisfeitos, a qual variava em diferentes países, ao invés de usar a nota absoluta proposta por Spanier (1976), Sharlin et al. (2000) propuseram trabalhar com os indicadores do próprio grupo, tendo-se adotado aqui tal estratégia. No presente trabalho, para um casal ser considerado satisfeito, ambos os cônjuges necessitaram ter pontuação igual ou superior a 42 na sub-escala de satisfação da Escala de Ajustamento Conjugal (DAS - Spanier, 1976), o que consiste em meio desvio padrão acima da média da amostra. Um resultado alto nessa escala indica compromisso com a continuidade do relacionamento e satisfação conjugal no momento atual. Por outro lado, para um casal ser considerado insatisfeito, bastou apenas que um dos cônjuges obtivesse pontuação igual ou inferior a 35 , ou seja, meio desvio padrão abaixo da média da amostra. De acordo com esses critérios, seis casais $(15,8 \%)$ foram classificados como satisfeitos e oito casais (21\%) considerados insatisfeitos. $\mathrm{O}$ que se percebe é que mais de um terço da amostra estudada se encontra nesses extremos da curva de distribuição $(36,8 \%)$.

Analisando o grupo como um todo, somente em um casal houve discrepância acentuada em relação à satisfação conjugal, ou seja, o marido estava satisfeito com o casamento e a mulher, insatisfeita. Este casal foi considerado insatisfeito, de acordo com os critérios mencionados. Nos demais casais, ou ambos os cônjuges se encontravam na mesma faixa de satisfação, ou um deles se encontrava num dos extremos (satisfeito ou insatisfeito) e o outro na faixa mediana. Apesar de os homens da amostra apresentarem pontuação pouco acima da obtida pelas mulheres em relação à satisfação conjugal, não foram observadas diferenças de gênero estatisticamente significativas entre ambos, diferentemente do ocorrido no estudo de Kaslow, Hanson, e Lundblad (1994), realizado com o mesmo procedimento na Suécia, e do sugerido no Brasil por Miranda (1987), apesar de a mesma não ter se detido especificamente em casamentos tão longos.

Embora, numa parcela pequena, ambos os cônjuges estejam satisfeitos com a sua relação $(15,8 \%)$, considerando-se os casais medianamente satisfeitos em que um dos cônjuges está nessa categoria (34\%), o índice de casais em que pelo menos um dos cônjuges está satisfeito com a relação passa a ser de $49,8 \%$. Ou seja, quase metade dos participantes parece estar de medianamente satisfeito a satisfeito com seu relacionamento conjugal. Enquanto isso, apenas um quinto dos casais que estão juntos há muito tempo continua casado, apesar de pelo menos um deles estar insatisfeito. Talvez esse quadro reflita uma mudança de mentalidade: as pessoas parecem estar juntas por opção e a qualidade do seu relacionamento parece ser importante para a durabilidade do casamento de muitos.

$\mathrm{O}$ instrumento utilizado permite que se identifiquem os recursos considerados importantes para entender os relacionamentos de longa duração, destacando-se: recursos sociais (1. contexto sócio-econômico do país; 2. contexto só- cio-cultural: grupo étnico e religioso), recursos individuais (1. história pessoal antes do casamento: infância, história do relacionamento dos pais, relacionamento com os próprios pais; 2. características pessoais: idade, educação, emprego, religião, saúde) e recursos do casal (1. contexto familiar: história da relação conjugal, estrutura da família, estágio da vida familiar, status econômico; 2. valores da família: motivos para permanecerem juntos, componentes da satisfação conjugal; 3. qualidade do relacionamento: ajustamento, consenso, coesão, expressão de afeto, proximidade, resolução de conflito, flexibilidade).

\section{Recursos individuais e sociais}

Quanto a informações relativas à história pessoal, obtidos no Questionário de Informações Gerais, não houve relação significativa entre estes itens e o nível de satisfação. No que se refere às características destes relacionamentos, cabe mencionar que nenhum dos casais insatisfeitos casou sob pressão e apenas um cônjuge, o qual está satisfeito com a sua relação, afirmou ter casado nessas circunstâncias. Alguns participantes (14) relataram casos extraconjugais esporádicos, sendo que metade dos casos narrados ocorreu entre os casais insatisfeitos. Note-se que em dois casais insatisfeitos, ambos os cônjuges narraram ter tido essas experiências. Os demais aconteceram entre os medianamente satisfeitos e tal prática não foi relatada pelos casais satisfeitos. Pode-se supor que dado o fato de o casamento ser satisfatório, os cônjuges tenham suas necessidades satisfeitas e, conseqüentemente, não haver razão para qualquer um deles buscar outro relacionamento. Também é possível hipotetizar que o valor religioso atue como um impedimento ou que não queiram mencionar tal prática, mesmo em um questionário não identificável.

Relativo à história do relacionamento com os pais antes do casamento, a maioria das pessoas declarou ter bastante proximidade ou, ao menos, proximidade moderada com os mesmos e baixo nível ou nenhum conflito tanto com o pai quanto com a mãe. Nota-se que, em média, o casamento dos pais foi longo (39,5 anos) e o nível de conflito percebido entre os membros do casal era baixo. Há autores que afirmam que o relacionamento dos pais nos anos de formação parece exercer influência sobre futuros relacionamentos dos filhos, servindo como modelo (Kaslow \& Hammerschmidt, 1992; Lewis \& Spanier 1979). Apesar de os dados obtidos nesse estudo indicarem haver baixo nível de conflito entre os pais dos casais satisfeitos e bom relacionamento entre pais e filhos, as informações obtidas são insuficientes para averiguar como, e se, o modelo familiar aprendido com a família de origem exerceu alguma influência na relação conjugal atual.

Comparando-se casais satisfeitos e insatisfeitos em relação a todos os resultados relativos a recursos sociais e individuais, foi encontrada relação significativa pela técnica de tabela de contingência, utilizando teste qui-quadrado com nível de confiança de $95 \%$, somente entre as variáveis praticante na religião e nível de satisfação do casal. Observou-se que a totalidade dos casais satisfeitos era praticante, enquanto entre os insatisfeitos, a maioria (61\%) não era praticante. 
Deve-se mencionar que a amostra a partir da qual foram obtidos os resultados do presente estudo era composta em sua grande maioria $(90 \%)$ de católicos e com alto índice de praticantes $(63 \%)$, o que gera a necessidade de maiores investigações considerando outras religiões nas quais o divórcio é aceito. Neste sentido, o fato de os casais satisfeitos serem na sua maioria católicos praticantes deve implicar que assumam realmente os valores de sua religião, ou seja, considerar o casamento um sacramento indissolúvel, com o qual devam se comprometer pela vida toda. Mas, também deve ser ressaltado que a filiação religiosa já se destacara como um recurso importante para a satisfação conjugal no estudo de Fenell (1987) realizado com protestantes e no estudo multicultural prévio (Sharlin et al., 2000) no qual foram estudados indivíduos que professavam diferentes credos (protestantes, católicos ou judeus).

Pode-se pensar que o sistema de crenças que se baseia nas religiões dá apoio para os membros do casal encararem o casamento como uma aliança, um compromisso. Foi observado nos oito países em que o estudo já foi realizado (Estados Unidos, Suécia, Alemanha, Holanda, Canadá, África do sul, Israel e Chile), que a crença religiosa ajuda cada um dos cônjuges a se comprometer tanto com a instituição do casamento quanto com o parceiro, inclusive nos momentos difíceis da relação, o que se supõe também ocorra em nosso país. Além disso, há que se considerar que casais praticantes em termos de religião supostamente devem fazer parte de uma comunidade, que constitui uma rede de apoio nos momentos de crise e reforça as expectativas em relação à permanência do relacionamento conjugal.

\section{Recursos do casal - qualidade do relacionamento}

$\mathrm{O}$ objetivo central do presente trabalho dizia respeito a identificar quais variáveis estariam correlacionadas à satisfação conjugal e os processos e características investigados foram avaliados por meio da Escala de Ajustamento Conjugal que, como um todo, avalia o ajustamento conjugal e seus subitens, que medem expressão de afeto, coesão, consenso e satisfação conjugal. Além disso, foi utilizado o Questionário de Avaliação de Estratégias de Resolução de Conflito e Comunicação, que avalia flexibilidade, comunicação, capacidade de resolução de problemas e consenso. Para distinguir o consenso avaliado pelo primeiro instrumento do consenso avaliado pelo segundo, ao fazer referência a este último será utilizado o termo proximidade.

Comparando-se os resultados dos casais satisfeitos e insatisfeitos na Escala de Ajustamento Conjugal, foram observadas diferenças significativas entre eles em relação aos itens de ajustamento global, expressão de afeto e coesão pela técnica estatística Análise de Variância (One-Way ANOVA) com teste $F$ e nível de confiança de $95 \%$ (vide Tabela 1 ).

Com relação aos resultados do Questionário de Avaliação de Estratégias de Resolução de Conflito e Comunicação, houve diferença significativa entre os casais satisfeitos e insatisfeitos pela técnica estatística de Análise de Variância (One-Way ANOVA) com teste $F$ e nível de confiança de $95 \%$ no tocante à solução de problemas, comunicação, flexibilida- de e proximidade (consenso). A pontuação dos casais satisfeitos e insatisfeitos aparece na Tabela 2.

Tabela 1

Comparação entre casais satisfeitos e casais insatisfeitos na Escala de Ajustamento Conjugal

\begin{tabular}{lcc}
\hline \multicolumn{1}{c}{$\mathrm{N}=76$} & Satisfeitos & Insatisfeitos \\
$\mathrm{N}=12$ & $\mathrm{~N}=16$ \\
\hline Total & $122,2\left(^{*}\right)$ & $95,2\left(^{*}\right)$ \\
Consenso & 50,3 & 44,2 \\
Satisfação & $44,2(*)$ & $31,5\left(^{*}\right)$ \\
Coesão & $18,5\left(^{*}\right)$ & 12,4 \\
Expressão de afeto & $9,2(*)$ & $7,1(*)$ \\
\hline
\end{tabular}

(*) diferença significativa - nível de confiança de 95\%

Tabela 2

Comparação entre casais satisfeitos e casais insatisfeitos no Questionário de Avaliação de Estratégias de Resolução de Conflitos e Comunicação

\begin{tabular}{llc}
\hline \multicolumn{1}{c}{$\mathrm{N}=76$} & Satisfeitos & Insatisfeitos \\
& $\mathrm{N}=12$ & $\mathrm{~N}=16$ \\
\hline Comunicação & $36,8(*)$ & $31,1(*)$ \\
Resolução de problemas & $35,7(*)$ & $30,5(*)$ \\
Flexibilidade & $40,3(*)$ & $33,9(*)$ \\
Proximidade (consenso) & $46,7(*)$ & $35,9(*)$ \\
\hline
\end{tabular}

(*) diferença significativa - nível de confiança de $95 \%$

Em síntese, ao levar em consideração tais dados, identifica-se que satisfação conjugal está associada a: ajustamento conjugal; expressão de afeto; coesão; proximidade; capacidade de resolução de problemas e habilidade de comunicação. O ajustamento conjugal dos casais satisfeitos parece ser mais funcional, provavelmente por existir maior coesão, proximidade e demonstração de afeto entre os cônjuges. Além disso, eles parecem dispor de melhores estratégias de resolução de conflitos e nível de comunicação, o que, por sua vez, pode colaborar para o ajustamento conjugal. As informações obtidas são congruentes com as pesquisas realizadas nos outros paises nos quais o presente procedimento foi aplicado (Sharlin et al. 2000), bem como em outros estudos sobre satisfação conjugal norte-americanos (Olson, 1988, 2000; Spanier \& Lewis, 1980) e brasileiros (Dela Coleta, 1989; Faria 1994; Miranda 1987).

A eficiência de todos os instrumentos utilizados foi confirmada através de outra técnica estatística, a árvore de correlações, por meio da qual verificou-se que as variáveis do grupo qualidade do relacionamento do casal (ajustamento conjugal; consenso; coesão; expressão de afeto; solução de problemas; comunicação; proximidade e flexibilidade) e qualidade da vida conjugal pareceram formar um sistema de variáveis relativamente independentes, pois apre- 
sentaram fortes correlações entre si. As variáveis que apresentaram maior correlação com satisfação conjugal foram ajustamento conjugal e felicidade do casal, fato que veio a confirmar a importância desses aspectos para a satisfação. A árvore também favorece perceber como o complexo de variáveis se organiza.

\section{Recursos do casal - valores da vida familiar: motivos para permanecer junto}

Dentre os motivos que levam os membros do casal a permanecerem juntos no momento atual e nos momentos de crise pelos quais passaram destacou-se como motivo principal, ou seja, escolha mais freqüente, o amor, tanto entre satisfeitos quanto entre insatisfeitos. Pergunta-se, portanto, se além do amor ser um aspecto importante do relacionamento, não se trata também de um ideal arraigado, apontado pelos participantes independentemente da satisfação que experimentam no relacionamento, atuando mais como crença do que como sentimento. A partir daí, as escolhas entre casais satisfeitos e insatisfeitos variam consideravelmente.

No momento atual, os casais satisfeitos identificaram como motivos para continuarem juntos, em primeiro lugar, ao lado do amor, a convicção de que o casamento é uma parceria para a vida toda; em segundo lugar aparece o fato de comple- tarem um ao outro, independentemente de tensões ocasionais; o cônjuge sempre ter se comportado sinceramente, mesmo nas situações de crise e serem pacientes e compreensivos um com o outro. Já os casais insatisfeitos apontaram, em ordem de preferência, em primeiro lugar o amor, como já foi mencionado, em segundo lugar o fato de sentirem-se responsáveis pelos filhos e o cônjuge sempre ter se comportado sinceramente, mesmo nos momentos de crise.

Nos momentos difíceis, além do amor, mencionado em primeiro lugar, os casais satisfeitos consideram importante, em segundo, o fato de o casamento ser uma parceria para a vida toda. Já os casais insatisfeitos com a sua relação deram como motivos para continuar juntos nos momentos difíceis, somente o amor em primeiro lugar e em segundo a convicção de que as crises são inevitáveis, e que crises promovem o crescimento pessoal.

$\mathrm{O}$ fato de casais satisfeitos, nos momentos difíceis, alegarem ter ficado juntos pelo compromisso assumido, pois acreditam que o casamento é uma parceria para a vida toda, é congruente com a crença religiosa que a maioria deles professa e vai ao encontro dos resultados do estudo multicultural realizado por Sharlin et al. (2000), particularmente no Chile, único pais também predominantemente católico, bem como com os resultados de Lauer et al. (1990) e Fennell (1987).

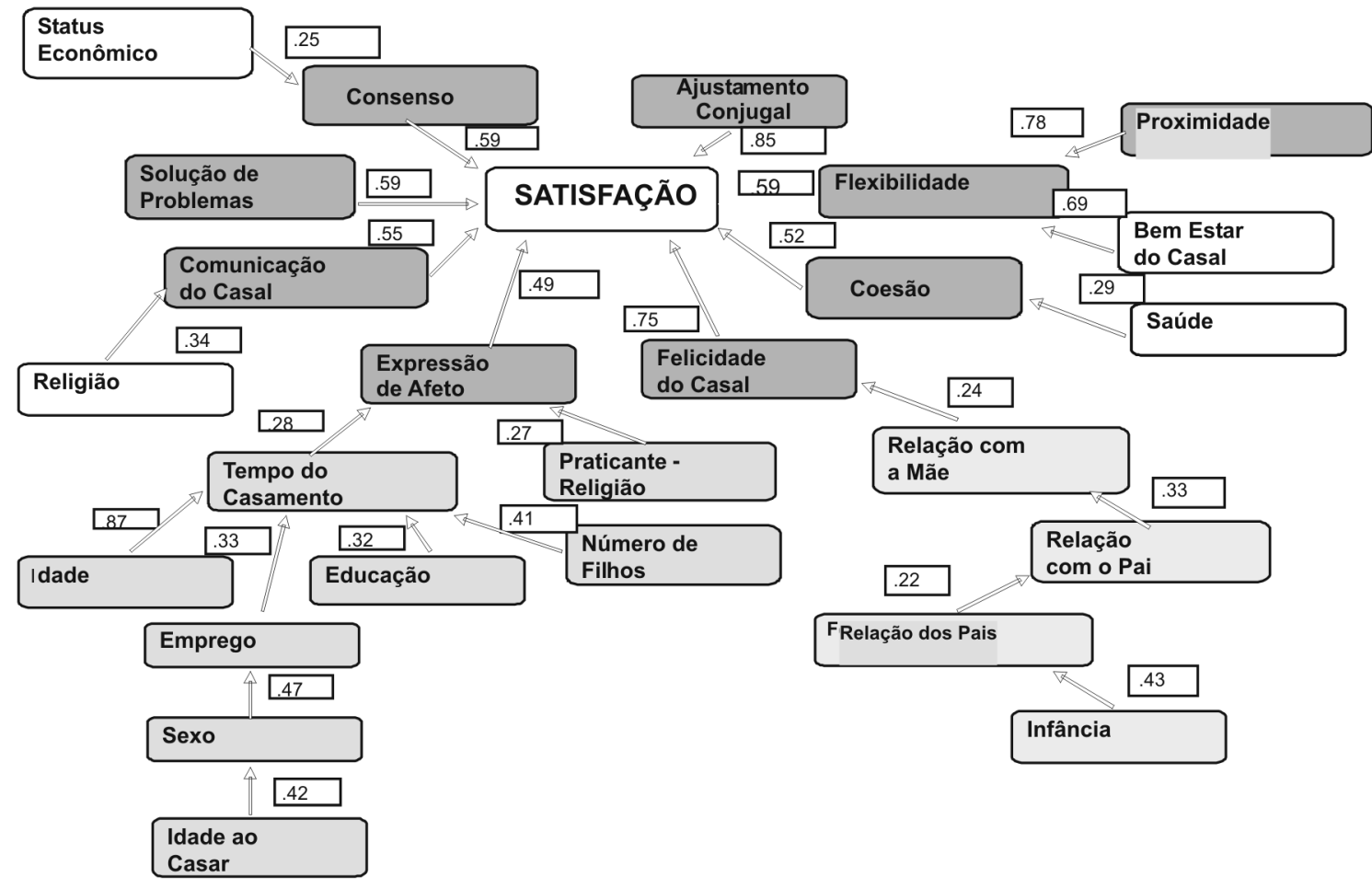

Figura 1. Árvore de correlações em que é possível perceber o agrupamento das variáveis (os números nos pequenos retângulos indicam o valor da correlação). 
Agrupando as escolhas em categorias, verificou-se que casais satisfeitos privilegiaram no momento atual, os motivos intrínsecos à relação, seguidos por motivos referentes a valores e crenças, bem como resolução positiva de problemas e, por último, motivos relativos ao parceiro. Nos momentos difíceis, essa ordem se altera e os motivos mais importantes foram os relativos a valores e crenças pessoais, seguidos por motivos intrínsecos referentes à relação conjugal e, por último, ao parceiro.

Casais insatisfeitos, no momento atual, apontaram como motivações para permanecerem na relação motivos intrínsecos, valores e crenças e em razão de normas e expectativas sociais. Nos momentos difíceis, escolheram em função de seus valores e crenças e motivos intrínsecos relativos à relação. Não levaram em consideração motivos relacionados ao parceiro, o que leva a crer que a percepção e a relação com o cônjuge sejam realmente áreas conflituosas. Além disso, privilegiaram motivos neuróticos para permanecerem juntos, tais como: terem medo de mudanças; terem medo de não conseguir se arranjar sozinho; e medo de que seu cônjuge não consiga se arranjar sozinho.

O que se observa é que casais satisfeitos com a sua relação, tanto em momentos difíceis como na atualidade, valorizaram a relação conjugal, assim como o parceiro, levando em consideração suas crenças e valores pessoais como motivo para permanecerem juntos. Para eles, também foi importante a capacidade de resolução positiva de problemas. Casais insatisfeitos também valorizaram motivos intrínsecos à relação, assim como valores e crenças pessoais para permanecerem juntos; contudo, pareceram estar mais sujeitos à pressão social (normas e expectativas sociais) e motivos neuróticos (sentir-se incapaz de viver sem o outro), bem como não levaram o cônjuge em consideração.

\section{Recursos do casal - valores da vida familiar: componentes importantes para a satisfação}

Foi apresentada, também, uma lista de itens na qual cada participante deveria assinalar se as características arroladas existiam ou eram desejadas no relacionamento conjugal. A totalidade dos casais satisfeitos mencionou existir na sua relação os seguintes itens: confiança e respeito mútuos; abertura, honestidade e integridade; gostar um do outro, concordância sobre comportamento sexual, tomar as principais decisões juntos, interesses compartilhados a respeito dos filhos, atratividade do cônjuge, humor e alegria juntos, bem como orientação espiritual semelhante. Posto os casais satisfeitos acreditarem existir no seu casamento várias das características arroladas, desejaram apenas algumas poucas (entre 0 e 4). O item que menos existia na relação conjugal satisfatória foi segurança econômica e, conseqüentemente, foi o mais desejado. Outros itens almejados foram: evitar a repetição e o tédio, e ter boa habilidade para resolver problemas.

Por outro lado, observa-se que a escolha dos que existiam no próprio relacionamento, por parte dos casais insatisfeitos, variou bastante. Nenhum item foi escolhido por todos, embora uma maioria significativa tenha mencionado a exis- tência de confiança. Esses casais desejaram vários componentes para o seu relacionamento, e 14 itens tiveram freqüência de escolhas alta, sendo que o número médio de itens desejados foi 10. Os aspectos mais desejados foram: concordância sobre comportamento sexual; satisfação sexual mútua, evitar a repetição e o tédio, bem como o equilíbrio entre individualidade e conjugalidade.

Note-se que, tanto casais satisfeitos quanto insatisfeitos, desejaram evitar a repetição e o tédio nos seus relacionamentos. Portanto, pode-se supor que essa questão prescinda do nível de satisfação conjugal e que evitar a repetição e o tédio seja relevante para relações duradouras, nas quais o convívio pode contribuir tanto para aproximar, quanto para distanciar o casal.

Em comum entre os participantes parece fundamental, para as relações conjugais de longa duração, que cada um dos cônjuges seja capaz de desenvolver seus potenciais, ao mesmo tempo em que consiga realizar trocas estimulantes com o parceiro, exercendo atividades e interesses comuns. Todos os casais (satisfeitos e insatisfeitos) consideraram essencial para a conjugalidade o relacionamento afetivo e a tomada de decisões em conjunto. Outros aspectos foram considerados por todos os participantes satisfeitos e por 14 dos 16 insatisfeitos, a saber: a sexualidade, permitir o desenvolvimento individual de cada um e interesse compartilhado pelos filhos.

Embora casais satisfeitos e insatisfeitos tenham demonstrado valorizar na relação conjugal princípios humanos universais, tais como: confiança, respeito e apoio mútuos; abertura, honestidade e integridade; lealdade e fidelidade; gostar um do outro; e interesse pelos filhos; parecem existir algumas diferenças entre eles. Os satisfeitos acrescentaram outras características importantes relativas ao cônjuge e à sua interação (concordar sobre comportamento sexual; ter estrutura clara de papéis e responsabilidades; achar o cônjuge atraente; ter humor e alegria juntos; e ter orientação espiritual semelhante), variáveis que apontam relacionamento com possibilidade de transformação.

\section{Fatores que corroboram para ocorrer a satisfação conjugal}

Para analisar se todos os dados apresentados no estudo são congruentes, realizou-se outra análise estatística, a regressão múltipla (stepwise), que verificou quais das variáveis estudadas têm maior influência na satisfação conjugal. Foi verificado serem elas: 1 . proximidade; 2 . solução de problemas; 3. coesão; 4. comunicação; 5. status econômico e 6. religião-praticante.

O coeficiente de determinação $\left(R^{2}\right)$ ajustado mostra a capacidade das variáveis listadas explicarem estatisticamente a variável-critério escolhida, no caso, a satisfação conjugal. $\mathrm{O}$ valor encontrado foi de $75,8 \%$, o que confirma a validade dos modelos de regressão múltipla. Isso significa que a probabilidade de existir satisfação conjugal aumenta se no relacionamento também houver proximidade, estratégias adequadas de resolução de problemas, coesão, boa habilidade de comunicação, se os cônjuges estiverem satisfeitos com o 
seu status econômico e se forem praticantes de sua crença religiosa.

\section{Considerações finais}

Casais satisfeitos parecem ser funcionais, tendo conseguido manter fortes laços emocionais com seu cônjuge, mudar a estrutura de poder, papéis e regras de seu relacionamento ao longo da vida conjugal e em face de situações de crise, assim como desenvolver padrões de comunicação adequados (Minuchin, 1990; Olson, 1988), o que é considerado por vários autores como essencial para a satisfação conjugal (Farias, 1994; Gottman \& Krokoff, 1989; Kaslow \& Robinson, 1996; Sharlin et al. 2000; Spanier \& Lewis, 1980).

Os resultados desta pesquisa são bastante similares aos de Sharlin et al. (2000) obtidos no estudo multicultural realizado em vários países e envolvendo o mesmo procedimento. Posto esses estudos terem sido realizados em países que sofreram influência da cultura judaico-cristã, os resultados podem ser similares por referirem-se a estes valores. Por outro lado, talvez o ser humano deseje coisas semelhantes para si mesmo, ou seja, ser amado, respeitado, sentir-se seguro, compartilhar desejos e sonhos, ter suas necessidades físicas, emocionais e espirituais satisfeitas, bem como, ter a possibilidade de dividir tudo isso com alguém especial ao longo da vida.

Relevante mencionar que a totalidade dos casais satisfeitos era católica praticante. Portanto, pode-se supor que eles realmente estejam comprometidos com a indissolubilidade do matrimônio. Além disso, os casais satisfeitos reiteraram a importância de sua crença religiosa nos momentos difíceis pelos quais passaram. Há que se lembrar também que tais casais se são praticantes, devem ter uma rede que lhes dê apoio nessas ocasiões, apontando a importância de se considerar variáveis contextuais, para além das intrapsíquicas e interpessoais na qualidade do relacionamento conjugal, pois também o status econômico mostrou-se fortemente associado à satisfação.

Como se pôde observar, o casamento pode ser uma construção conjunta da realidade, uma opção viável de relacionamento que corresponda às expectativas de cada um dos parceiros, se cada um deles se comprometer com sua escolha e acreditar no que está fazendo. Pelo visto, para que um relacionamento conjugal continue satisfatório ao longo dos anos, há necessidade de investir na relação, empenhando-se para que ela seja proveitosa para os dois, tentando encontrar equilíbrio entre conjugalidade e individualidade, partilhando interesses e relacionamento afetivo-sexual, buscando evitar o tédio e a repetição.

Todos os cônjuges satisfeitos e insatisfeitos, homens e mulheres, deram como motivo para permanecer na relação, o amor. Isso parece confirmar o valor que o amor-paixão romântico desempenha na cultura ocidental atual. Busca-se a alma gêmea, a cara-metade e, ao ser encarado desse modo, o amor deixa de ser apenas um atributo importante da relação conjugal, tornando-se algo sem o qual não se vive. Almejando compartilhar a vida com alguém especial espera-se viver feliz para sempre: relações conjugais duradouras e satisfatórias.
Contudo, é importante perceber que a relação conjugal é uma construção e que, ao casar, o trabalho está apenas começando. Casamento satisfatório, como o presente estudo demonstrou, é menos uma questão de escolha certa e mais de trabalho em equipe. Enquanto o trabalho pode ser aprimorado, a escolha só pode dar origem a outras, talvez tão pouco satisfatórias quanto a anterior.

Os resultados dessa pesquisa podem ajudar a nortear a prática clínica e trabalhos de promoção de saúde, pois as variáveis interpessoais que parecem corroborar para que os casamentos de longa duração sejam satisfatórios - consenso, resolução de conflito, comunicação, flexibilidade, entre as principais - podem ser aperfeiçoadas ou adquiridas, melhorando a qualidade de vida individual e conjugal.

Ao realizar esta pesquisa, foi importante constatar que existem casamentos de longa duração satisfatórios; que pessoas casadas há muito tempo permanecem se importando com seus companheiros(as), ainda amam um ao outro e consideram-se amigos. Foi interessante perceber como existem valores, objetivos e modo semelhantes de encarar a vida, o que também é conquistado. Parecem estar envolvidos com as questões atuais do seu relacionamento, tentando buscar alternativas para evitar a rotina e continuar se desenvolvendo. Os casais satisfeitos demonstraram que seu casamento permanece vivo, em transformação, pois eles continuam a investir no mesmo e a acreditar que é possível estar casado há muito tempo e continuar unido para o que der e vier.

\section{Referências}

Campbell, A., Converse, P. E., \& Rogers, W. L. (1976). The quality of American life. Nova York: Russel Sage Foundation.

Chadwick, B. A., Albrecht, S. L., \& Kunz, P. R. (1976). Marital and family role satisfaction. Journal of Marriage and the Family, 38(3), 431- 440.

Dela Coleta, M. F. (1989). Locus de controle e satisfação conjugal. Dissertação de mestrado não- publicada, Universidade de Brasília, Brasília.

Farias, M. A. (1994). Satisfação e insatisfação no casamento: um estudo quantitativo. Tese de doutorado não-publicada, Universidade de São Paulo, São Paulo.

Fennell, D. L. (1987). Characteristics of long-term first marriages [Resumo]. In America Association for Marriage and Family Therapy (Org.), $45^{\text {th }}$ Annual Conference Book of Abstracts (p. 418). Chicago: Autor.

Gagnon, M. D., Hersen, M., Kabacoff, R. I., \& Van Hasselt, V. B. (1999). Interpersonal and psychological correlates of marital dissatisfaction in late life: a review. Clinical Psychological Review, 19(3), 359-378.

Gottman, J. M. (1994). What predicts divorce? The relationship between marital process and marital outcomes. Hillsdale: Lawrence Erlbaum.

Gottman, J. M., \& Krokoff, L. J. (1989). Marital interaction and satisfaction: a longitudinal view. Journal of Consulting and Clinical Psychology, 57(1), 47-62.

Hicks, M., \& Platt, M. (1970). Marital happiness and stability: a review of research in the 60's. Journal of Marriage and the Family, 32, 553-574.

Instituto Brasileiro de Geografia e Estatística. (2001). Estatísticas do Registro Civil. Disponível em http://www.sidra.ibge.gov.br/bda/regciv/defaut. Acesso em agosto de 2003.

Kaslow, F., \& Hammerschmidt, H. (1992). Long-term "good" marriages: the seemingly essential ingredients. Journal of Couples Therapy, 3(2/3), 15-38.

Kaslow, F., Hanson, K., \& Lundblad, A. M. (1994). Long-term marriages in Sweden: and some comparisons with similar couples in the United States. Contemporary Family Therapy, 16(6), 521-537. 
Kaslow, F., \& Robinson, J. A. (1996). Long-term satisfying marriages: perceptions of contributing factors. The American Journal of Family Therapy, 24(2), 153-170.

Lauer, R., Lauer, J., \& Kerr, S. (1990). The long-term marriage: perceptions of stability and satisfaction. International Journal of Aging and Human Development, 31(3), 189-195.

Lewis, R. A., \& Spanier, G. B. (1979). Theorizing about the quality and stability of marriage. In W. R. Burr, R. Hill, F. I. Nye, \& L. I. Reiss (Org.), Contemporary theories about the family (Vol. 1, pp. 268-294). Nova York: The Free Press.

Mcnamara, M. L .L., \& Bahr, H. M. (1980). The dimensionality of marital role satisfaction. Journal of Marriage and the Family, 42(1), 45-55.

Minuchin, S. (1990). Famílias - funcionamento e tratamento. Porto Alegre: Artes Médicas.

Miranda, E. S. (1987). Satisfação conjugal e aspectos relacionados: a influência da comunicação, da semelhança de atitudes e da percepção interpessoal. Arquivos Brasileiros de Psicologia, 39(3), 96-107.

Notarius, C., \& Markman, H. (1993). We can work it out-making sense of marital conflict. Nova York: Putnam's Sons.

Olson, D. H. (1986). Circumplex modell VII: validation studies and FACES III. Family Process, 25(3), 337-351.

Olson, D. H. (1988). Family types, family stress and family satisfaction: a family development perspective. In C. J. Falicov (Org.), Family transitions: continuity and change over the life cycle (pp. 55-80). Nova York: Guilford.

Olson, D. H. (2000). Circumplex model of marital and family systems. Journal of Family Therapy, 22, 144-167.

Olson, D. H., \& Stewart, K. L. (1991). Family systems and health behaviors. In H. E. Schroeder, (Org.), New directions in health psychology assessment (pp. 27-64). Nova York: Hemisphere.

Rollins, B., \& Cannon, K. (1974). Marital satisfaction over family life cycle: a reevaluation. Journal of Marriage and the Family, 36(2), 271-282.

Rollins, B., \& Feldman, H. (1970). Marital satisfaction over the family life cycle. Journal of Marriage and the Family, 32(1), 20-28.

Sharlin, A. S, Kaslow, F., \& Hammerschmidt, H, (2000). Together through thick and thin: a multinational picture of long-term marriages. Nova York: The Haworth Clinical Practice Press.

Spanier, G. B. (1976). Measuring dyadic adjustment: new scales for assessing the quality of marriage and similar dyads. Journal of Marriage and the Family, $38(1), 15-28$.

Spanier, G. B., \& Lewis, R. A. (1980). Marital quality: a review of the seventies. Journal of Marriage and the Family, 42(4), 825-839.

Weigel, D. J., \& Ballard-Reisch, D. S. (1999). How couples maintain marriages: a closer look at self and spouse influences upon the use of maintenance behaviors in marriages. Family Relations, 48(3), 263-269.

Weishaus, S., \& Field, D. (1988). A half century of marriage: continuity or change? Journal of Marriage and the Family, 50(3), 763-774.

Maria de Betânia Paes Norgren, mestre em Psicologia Clínica pela Pontifícia Universidade Católica de São Paulo, é professora no Instituto Sedes Sapientiae, em São Paulo. E-mail: norgren@uol.com.br

Rosane Mantilla de Souza, doutora em Psicologia Clínica pela Pontifícia Universidade Católica de São Paulo, é professora no Programa de Estudos Pós Graduados em Psicologia Clínica da Pontifícia Universidade Católica de São Paulo. Endereço para correspondência: Pontifícia Universidade Católica de São Paulo, Programa de Pós-Graduação em Psicologia Clínica; Rua Monte Alegre, 984 (Perdizes); São Paulo, SP; CEP 05015901. Tel.: (11) 3670-8521. Fax: (11) 3670-8521. E-mail: rosane@ pucsp.org

Florence Kaslow, doutora por Bryn Mawr College (Pensilvânia, EUA), é diretora do Florida Couples and Family Institute, Duke University (EUA).

Helga Hammerschmidt, doutora pela Ludwig Maxmilian Universitat (Munique, Alemanha) é pesquisadora no Centro de Transplantes da Clínica Grosshadern (Munique, Alemanha).

Shlomo A. Sharlin, doutor em Serviço Social pela University of Georgia (EUA), é pesquisador no Centro para Pesquisa e Estudo da Família, Escola de Serviço Social, Universidade de Haifa (Israel). 